\title{
Characteristics of CA Resist in EUV Lithography
}

\author{
Kazuhiro Hamamoto', Takeo Watanabe', Hideo Hada', \\ Hiroshi Komano ${ }^{2}$ and Hiroo Kinoshita ${ }^{1}$ \\ ${ }^{1}$ Laboratory of Advanced Science and Technology for Industry, \\ Himeji Institute of Technology \\ 3-1-2 Kouto, Kamigori-cho, Ako-gun, Hyogo 678-1205,Japan \\ ${ }^{2}$ Advanced Material Development Devision 2, Tokyo Ohka Kogyo Co., Ltd., \\ 1590, Tabata, Samukawa-cho, Kohza-gun, Kanagawa Pref. 253-0114,Japan
}

\begin{abstract}
According to the synchronous scanning of the mask and wafer with EUVL laboratory tool (ETS-1) with reduction optical system which consisted of three-aspherical-mirror in the NewSUBARU facilities succeeded in the line of $60 \mathrm{~nm}$ and the space pattern formation in the exposure region of $10 \mathrm{~mm} \times 10 \mathrm{~mm}$.

Comparing the result of exposure characteristics for positive-tone resist for $\mathrm{KrF}$ and $\mathrm{EB}$, $\mathrm{KrF}$ chemically amplified resist has better characteristics than EB chemically amplified resist. The development of suitable resist for EUVL that the resolution performance and sensitivity are good, and the amount of outgassing is low will be advanced based on $\mathrm{KrF}$ resist.
\end{abstract}

Keywords: Extreme Ultraviolet Lithography, large field exposure, CA resist

\section{Introduction}

The semiconductor industry plays a very important role in the information technology (IT). According to the SIA roadmap, by the year of 2006, minimum feature size of $70 \mathrm{~nm}$ on wafer is required. The extreme ultraviolet lithography $(E U V L)^{1)}$ is a promise technology for fabricating a fine pattern less than $70 \mathrm{~nm}$. This technology has to be developed in the pilot line until 2004 to meet this schedule ${ }^{2)}$. In 1999, we had fabricated 56-nmwidth line and space pattern in the exposure area of $10 \mathrm{~mm} \times 2 \mathrm{~mm}$ in size in the static exposure utilizing ETS-0 $0^{3,4)}$ which consists of threeaspherical-mirror imaging optics ${ }^{5}$. However, as for the practical use, it is very important that both to achieve large exposure area and to fabricate fine patterns. The exposure test standing ETS-1 was developed in Himeji Institute of Technology which consists of three-aspherical-mirrors, objective, and the mask and wafer scanning stages. Using the mask and wafer scanning stages, pattern width of less than $70 \mathrm{~nm}$ can be achieved in the exposure area of $30 \mathrm{~mm} \times 28 \mathrm{~mm}$ in size. The optical housing was made of invar to decrease the affect of the thermal expansion. Furthermore, we have proposed an EUVL mask with $\mathrm{Cr}$ absorber pattern. The $\mathrm{Cr}$ mask absorber pattern wet-etching technology for the optical lithography is extended to use that for the EUV lithography. In static exposure using $\mathrm{Cr}$ mask, 60-nm-width line and space pattern, 40-nm-width isolated line and 150nm-width hole pattern were reaplicated ${ }^{6}$.

The chemically amplified resist for EUV lithography requires following characteristics: 70 $\mathrm{nm}$ or less resolution, size accuracy $10 \mathrm{~nm}$ or less, sensitivity for $13-14 \mathrm{~nm}$ is $10 \mathrm{~mJ} / \mathrm{cm}^{2}$ or less, low edge roughness, a environmental, low outgassing, and wall slope $85^{\circ}$ or more. However, resist for EUVL has not optimized yet.

In this paper, we describe the fine pattern replication in the scanning exposure utilizing ETS1 three-aspherical-mirror imaging system. Furthermore, we describe the exposure characteristics of the positive-tone resist in EUVL based on the suitable resist for $\mathrm{KrF}$ and $\mathrm{EB}$.

The development of the ETS- 1 was performed in collaboration with the Association of SuperAdvanced Electronics Technologies (ASET). And 
the development of the chemically amplified resist was performed in collaboration with Tokyo Ohka Kogyo Co., LTD.

\section{Large-Field Exposure}

2.1. ETS-1 laboratory tool

Figure 1 shows the configuration of the ETS1 , respectively.

This system operated at the wavelength of $13.5 \mathrm{~nm}$. Numerical aperture is 0.1 . The resolution on the wafer estimated to be $60 \mathrm{~nm}$. The depth of focus is $1.9 \mu \mathrm{m}$ for a $0.1 \mu \mathrm{m}$ line and space pattern. The magnification of the imaging optics is $1 / 5$. The 8 inches wafer can be used. Furthermore, 8 inches mask and 6025 ULE reticule can be used. The vacuum environment is necessary for the exposure. The whole system consists the illumination optics, the scanning and the alignment mechanisms, the three-aspherical-mirror optics ${ }^{7}$. These whole mechanism are set on the vibration isolated activated bench to protect from the vibration affect. Furthermore the load-lock chamber for exchanging wafer is connected to the vacuum chamber of the EUVL laboratory tool. This tool is installed in a thermal chamber which is located at the end of the beamline $\mathrm{BL}^{9)}$ at the NewSUBARU synchrotron facility ${ }^{8}$. The thermal chamber keep the clean degree of class 100 which can be controlled the temperature within $23 \pm 0.5^{\circ} \mathrm{C}$.

The illumination optics that consists of two glancing mirrors was designed to satisfy the illumination area size of $50 \mathrm{~mm} \times 10 \mathrm{~mm}$ on the mask. The first mirror of illumination optics has a rotating mechanism, and it was rotated while exposing. Futhermore, to achieve the uniform dose in the illuminated area, the first illumination $\mathrm{C1}$ mirror is rotated while the exposure, and obtained uniform pattern in the exposure area of $10 \mathrm{~mm} \times 1$ $\mathrm{mm}$.

The resist was spin coated with on Si wafer of 8-inch diameter. Using the coating-and-developing system of Clean Track Mark-8 (Tokyo Electron Ltd.) carried out resist coating and development. Table 1 shows the condition of resist coating and developing process. The wafer surface treatment by HMDS $\left(90^{\circ} \mathrm{C}\right.$ and 60 seconds) was done before coating the resist. The resist thickness was measured by utilizing the thickness-measuring system of NANOMETRICS M5100A. The Si wafer coated with resist was settled in the exposure system and was exposed. The first mirror of illumination optics was rotated while exposing. After the development, CD measurement of the resist pattern was carried out by utilizing scanning electron microscope S-8840 (Hitachi Co. Ltd.). Furthermore, the observation of the absorber pattern on a Mo/Si multilayer was carried out by utilizing SEM S-4500 (Hitachi Co. Ltd.). Using this exposure tool, 60-nm-width line and space, 40$\mathrm{nm}$-width isolated line and 150-nm-width hole pattern has replicated on a wafer. ${ }^{6}$ )

\subsection{Exposure results}

The exposure area in static exposure is $10 \mathrm{~mm}$ $\times 1 \mathrm{~mm}$ in size. Replicated resist pattern width on a wafer was magnified in the reduction ratio of $1 / 5$ in comparison with the mask absorber pattern.

To extend the exposure area in the vertical

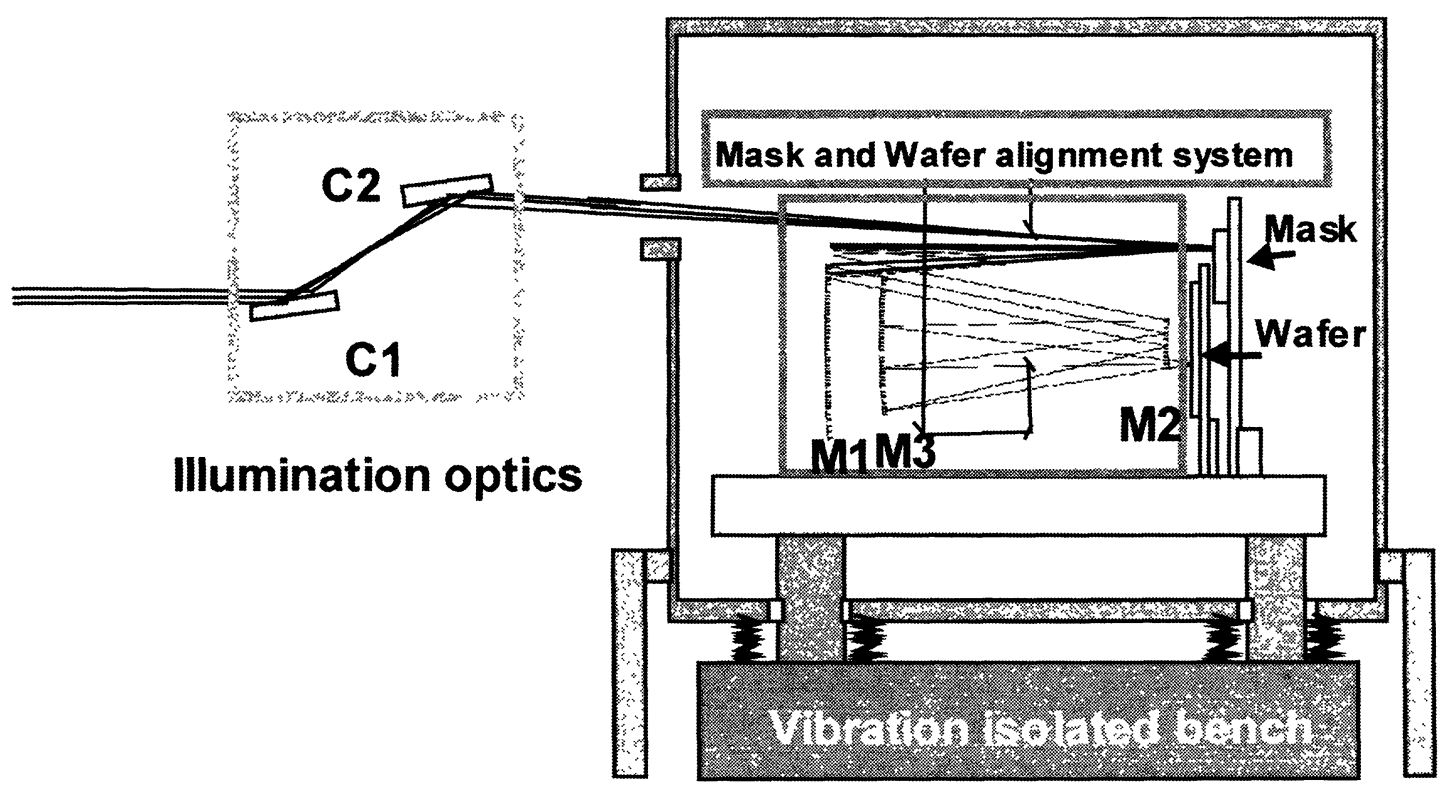

Fig 1. Configuration of the ETS-1 laboratory tool. 
direction, the mask and wafer stage were synchronized-scanned in the vertical direction. The mask stage moved 5.02 times faster than the wafer stage. This scanning ratio obtained by the length of the vertical direction of the replicated pattern becomes $1 / 5$ of the vertical direction of the pattern on the mask. As shown in Figure 2, it is achieved that the $100-\mathrm{nm}$-width of line and space pattern and the 60-nm-width of line and space pattern, in the exposure area of $10 \mathrm{~mm} \times 10 \mathrm{~mm}$ in size. It is confirmed that the ETS- 1 system has a capability to fabricated 60 -nm-node lithography with the mask and wafer stages with synchronized scanning. However, the dose uniformity was not so good, because the carbon contamination was deposited on the mask, which due to the hydrocarbon. The mask contamination appeared in the term of total two months in static exposure. Typical vacuum total pressure pressure and the hydrocarbons of 2 $\times 10^{-5} \mathrm{~Pa}$ and $1 \times 10^{-6} \mathrm{~Pa}$,respectively. In the next stage, the contamination control has to be investigated.

\section{Evaluation of CA resist characteristics}

\subsection{Uilized resist for this experiment}

The chemically amplified (CA) resist ${ }^{10)}$ for EUV lithography requires as follows characteristics: resolution is $70 \mathrm{~nm}$ or less, size accuracy $10 \mathrm{~nm}$ or less, sensitivity for $13-14 \mathrm{~nm}$ is $10 \mathrm{~mJ} / \mathrm{cm}^{2}$ or less, low edge roughness, a high environmental stability, low outgassing, and wall slope angle of greater than $85^{\circ}$ or more. However, resist for EUVL has not optimized yet.

ZEP520 (Nippon Zeon Co., Ltd.) positive-tone resist for $\mathrm{EB}$ that is non-CA resist has high resolution and chemical high environmental stability. However, sensitivity and contrast of ZEP520 is small ${ }^{6}$. Therefore, CA positive-tone resist is investigated in the exposure characteristics.

\subsection{Evaluation results and discussions}

Chemically amplified positive-tone resist from A to D (Tokyo Ohka Kogyo Co., Ltd.) are listed in table 1. Table 1 shows the resist processing conditions for these resists.

We obtained that the photospeed of the resist $A$ is $9.0 \mathrm{~mJ} / \mathrm{cm}^{2}$ which is described in reference 11). The photospeeds in table 2 are computed based on the sensitivity of the resist A multiply by the relative exposure time ratio. The photospeed of EB resist is smaller than $\mathrm{KrF}$ resist. The photospeed of ZEP520 is one order larger than that of CA resists.

Figure 3 and 4 show the SEM photograph of $120 \mathrm{~nm}$ width lines and spaces patterns and $80 \mathrm{~nm}$ width lines and spaces patterns of each resists, respectively. In this experiment, the resist processing condition was optimized by the purpose of decreasing edge roughness rather than the obtaining high resolution. The prebake temperature was raised to decrease the film losses, the amount of the residual solvent was decreased and the diffusion of the acid was controlled. The PEB temparature was lowered to shorten the diffusion length of the acid and to decrease the film losses. To decrease the film losses, the development time was shortened.As shown in table 2, the photospeed of the resist $C$ and $D$ are higher than that of the resist $\mathrm{A}$ and $\mathrm{B}$. Therefore, amount of generate acid in the resist $\mathrm{C}$ and $\mathrm{D}$ during exposure is larger than that the resist $\mathrm{A}$ and $\mathrm{B}$. Thus, the lost of the film

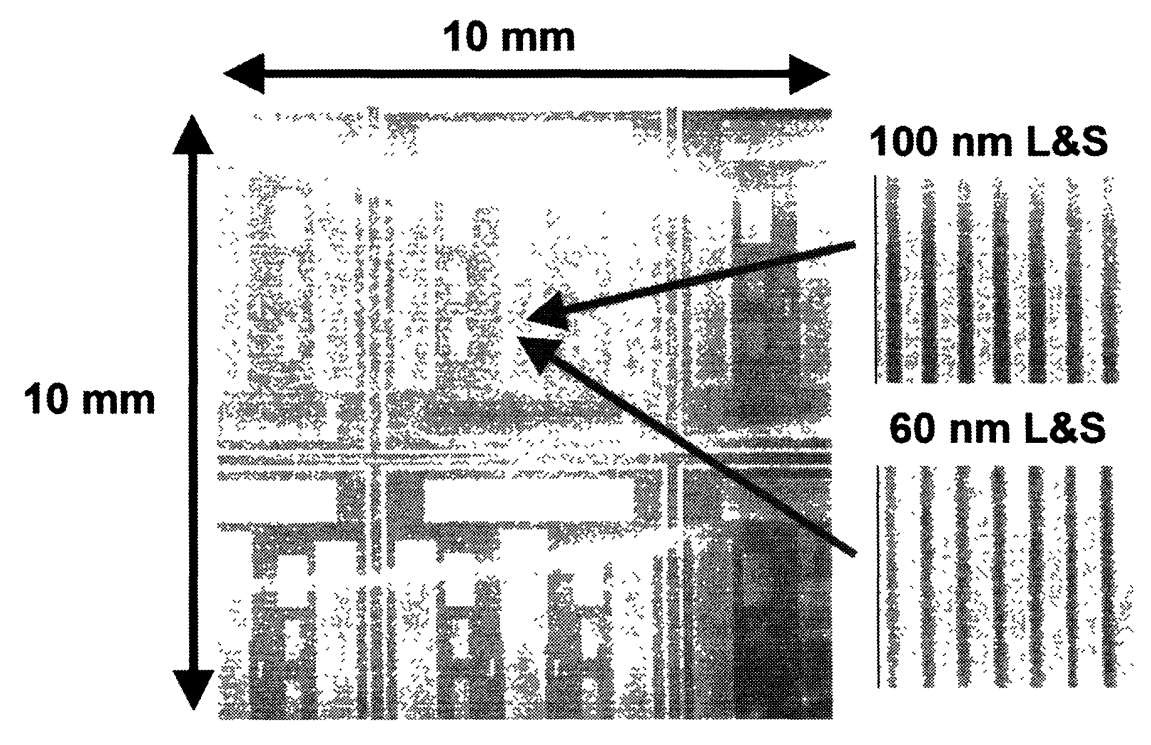

Fig. 2 Large field exposure pattern of ZEP520. 
Table 1. Resist processing conditions.

\begin{tabular}{|c|c|c|c|c|c|}
\hline & type & Prebake & PEB & Development & Rinse \\
\hline resist A & KrF-CA & $130^{\circ} \mathrm{C}, 90 \mathrm{~s}$ & $110^{\circ} \mathrm{C}, 90 \mathrm{~s}$ & $60 \mathrm{~s}$ (NMD-3) & de-ionized water \\
\hline resist B & KrF-CA & $120^{\circ} \mathrm{C}, 90 \mathrm{~s}$ & $140^{\circ} \mathrm{C}, 90 \mathrm{~s}$ & $45 \mathrm{~s}$ (NMD-3) & de-ionized water \\
\hline resist C & EB-CA & $150^{\circ} \mathrm{C}, 90 \mathrm{~s}$ & $130^{\circ} \mathrm{C}, 90 \mathrm{~s}$ & $45 \mathrm{~s}$ (NMD-3) & de-ionized water \\
\hline resist D & EB-CA & $140^{\circ} \mathrm{C}, 90 \mathrm{~s}$ & $130^{\circ} \mathrm{C}, 90 \mathrm{~s}$ & $45 \mathrm{~s}$ (NMD-3) & de-ionized water \\
\hline ZEP520 & EB-non CA & $180^{\circ} \mathrm{C}, 180 \mathrm{~s}$ & - & $240 \mathrm{~s}$ (o-xylene) & IPA \\
\hline
\end{tabular}

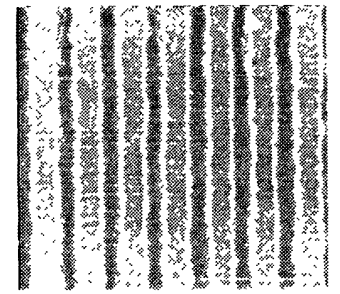

resist $A$

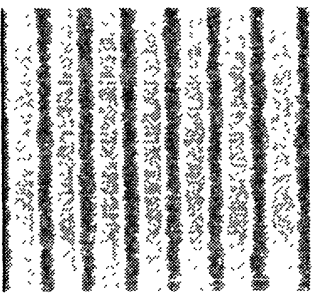

resist B

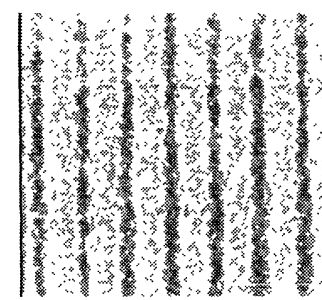

resist $\mathbf{C}$

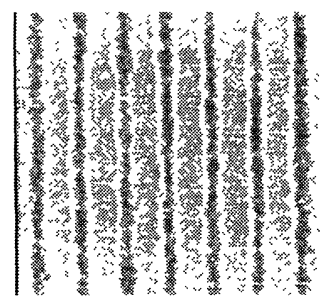

resist D

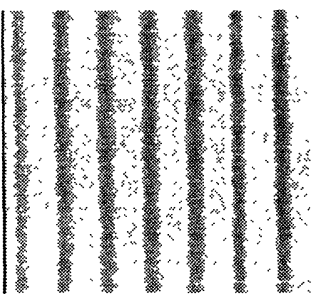

ZEP520

Fig. 3 120-nm-width line and space pattern.

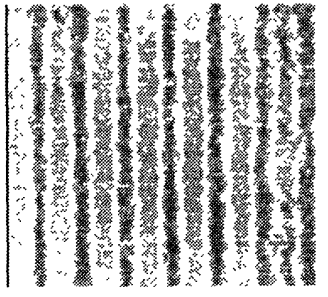

resist $\mathrm{A}$

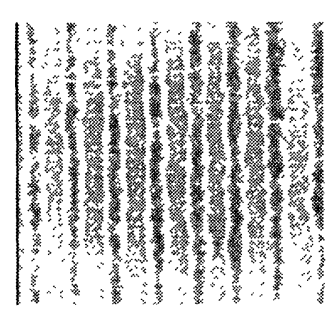

resist $B$

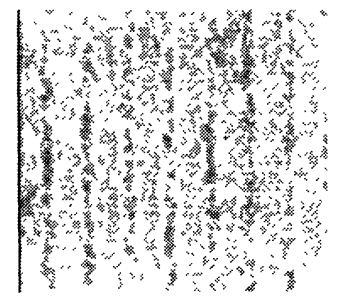

resist $\mathrm{C}$

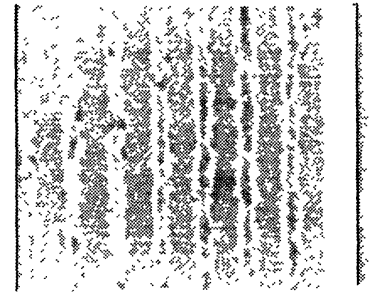

resist $D$

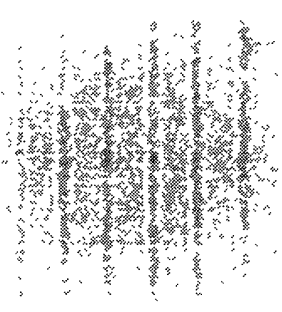

ZEP520

Fig. $4 \quad 80-n m-w i d t h$ line and space pattern.

thickness during development affects the edge roughness. The thickness of the resist $\mathrm{C}$ and $\mathrm{D}$ change $10-15 \%$ during development.

The results of the resist characteristics CA positive-tone resist optimized for $\mathrm{KrF}$ has better characteristics rather than those for EB. As shown in Figure 3 and 4, resolution capability of the resist $A$ and $B$ has less than $60 \mathrm{~nm}$.

EUV lithography requires the vacuum environment for the exposing the resist. By EUV irradiation, outgassing species due to hydrocarbons decompose to the carbon which contaminate on the mask surface and the reflective mirror surface. As a result, these reflectivity become lower. Therefore, the low outgassing resist is required. The outgassing experiment was carried out at the ETS1 chamber. The exposure area on a wafer was 10 $\mathrm{mm} \times 1 \mathrm{~mm}$ in size. The M-QA200F quadruple mass spectrometer (ANELVA Co., Ltd.) was connected to the ETS-1 chamber to detect the outgassing ion species from the resist. The typical base pressure in the ETS-1 chamber is maintained at $2.4 \times 10^{-5} \mathrm{~Pa}$. For each resist, partial pressure displacement is obtained by subtracting the partial pressure after exposure to that before exposure for the mass number from 1 to 60 . In order to obtain the amount of real partial pressure of outgas, the following equation is used.

Resist outgassing $=(($ just beginning of irradiation $)$

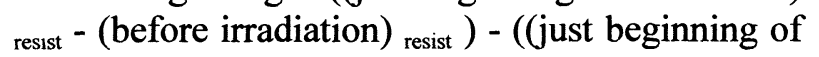
irradiation $)_{\mathrm{S}_{1} \text { wafer }}$ - (before irradiation) $)_{\mathrm{S} 1 \text { wafer }}$ )

Resist outgassing by EUV irradiation is shown in Fig. 5. Partial pressure displacement of ZEP520 shows a lot of hydrocarbon greater than $44 \mathrm{amu}$.

The amounts of outgassing of hydrocarbons from CA resist for $\mathrm{KrF}$ is higher than that for EB. It has been understood that the outgassing of CA resist is chiefly due to the decomposition of the protecting group as a result by the measurement of outgassing as described in reference 12) and 13). The amounts of outgassing of hydrocarbons from $\mathrm{CA}$ resist for $\mathrm{KrF}$ is higher than that for $\mathrm{EB}$. The protecting group decomposes easier from the resist $\mathrm{A}$ and $\mathrm{B}$ compare with the resist $\mathrm{C}$ and $\mathrm{D}$. 


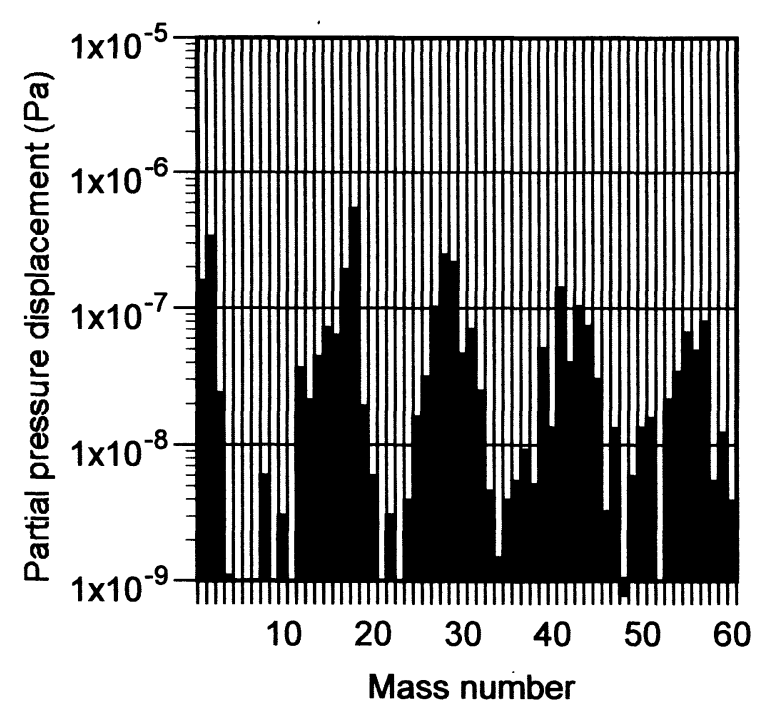

(a) resist $A$

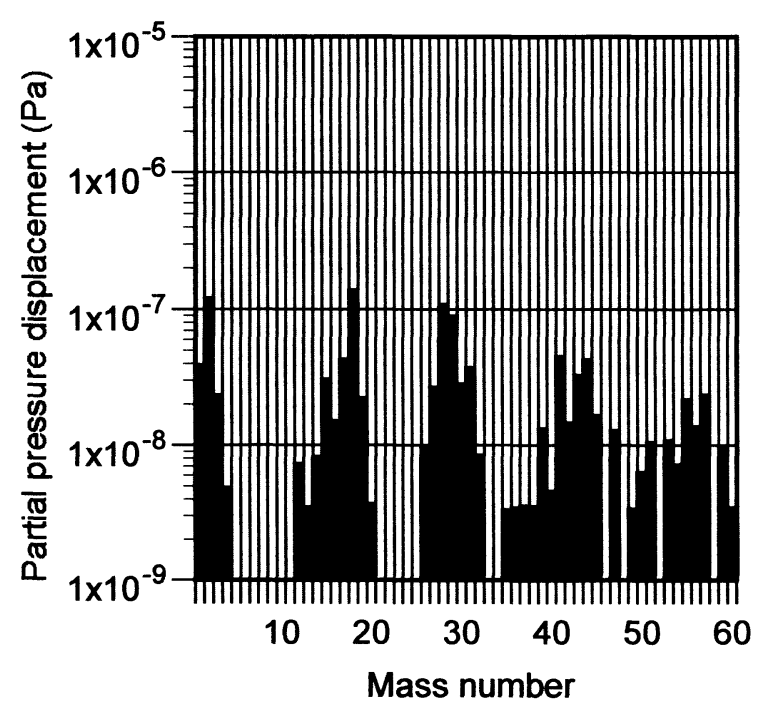

(c) resist $\mathrm{C}$

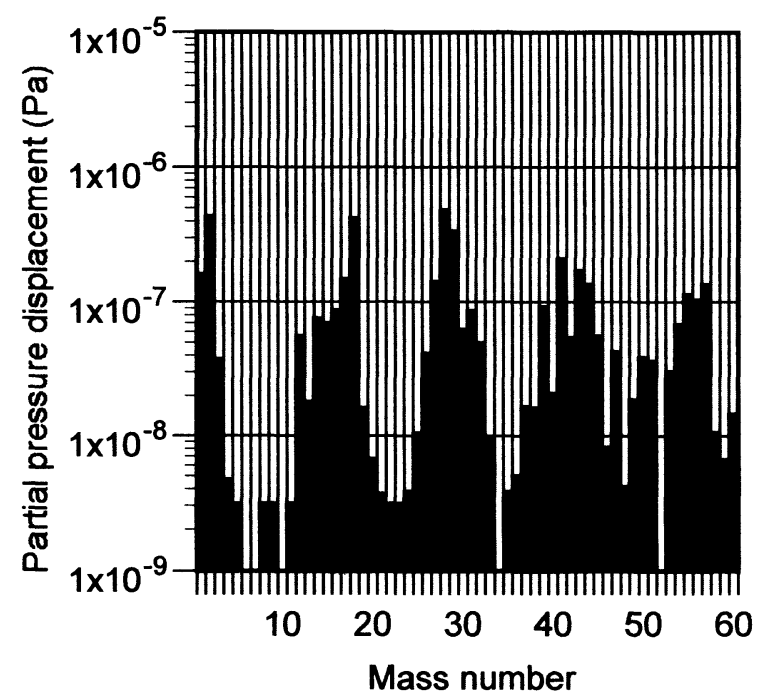

(e) ZEP520

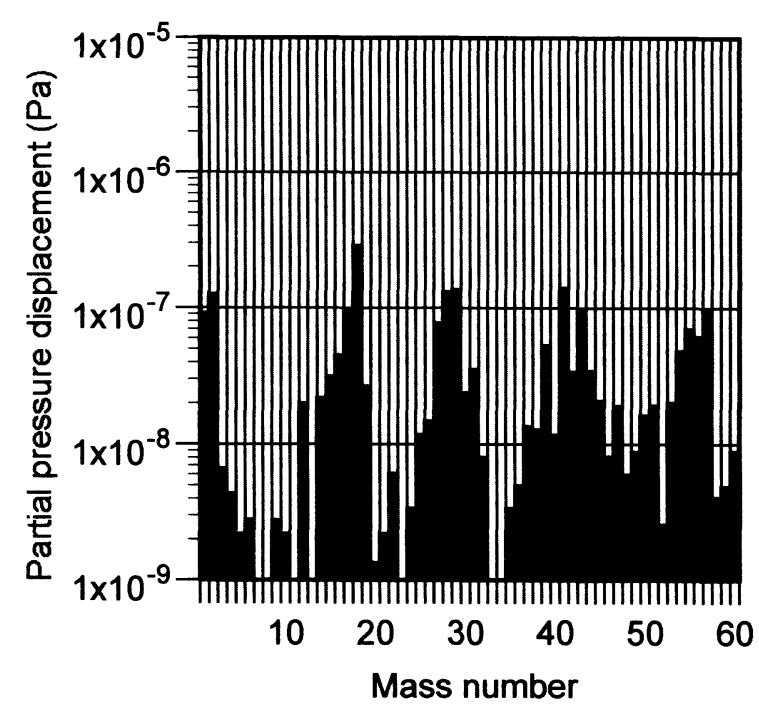

(b) resist $B$

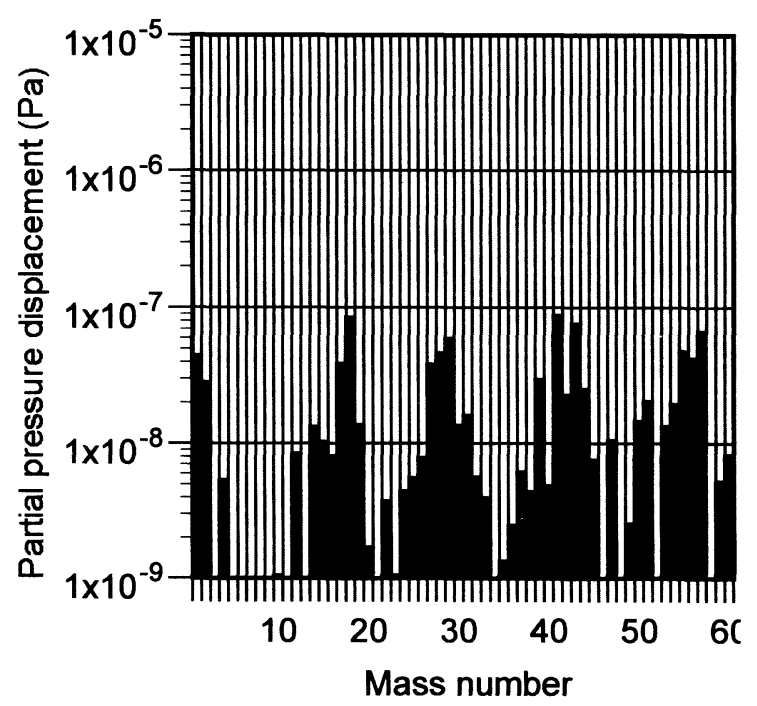

(d) resist D

Fig. 5 resist outgassing by EUV irradiation. 
Table 2. Characteristics of the resist.

\begin{tabular}{|c|c|c|c|c|c|}
\hline resist & Type & photospeed $\left(\mathrm{mJ} / \mathrm{cm}^{2}\right)$ & edge roughness & resolution & outgassing \\
\hline resist A & $\mathrm{KrF}$ & 9.0 & middle & $\leqq 60 \mathrm{~nm}$ & middle \\
\hline resist D & $\mathrm{KrF}$ & 5.7 & small & $\leqq 60 \mathrm{~nm}$ & middle \\
\hline resist B & EB & 2.0 & large & $80 \mathrm{~nm}$ & low \\
\hline resist C & EB & 1.8 & large & $80 \mathrm{~nm}$ & low \\
\hline ZEP520 & EB & 42.0 & small & $60 \mathrm{~nm}$ & high \\
\hline
\end{tabular}

Therefore it is considered that the amount of outgassing from CA resist depends on the protecting group of resist and does not depend on the sensitivity because the displacement of the partial pressure of just before and just after irradiation is obtained. The characteristics of the resist are shown in Table 2.

Totally resist characteristics presents the resist $B$ has best exposure characteristics in the evaluated resist. However, the outgassing has to be refined.

\section{Conclusions}

Using the mask and wafer stage with synchronized-scanned in the vertical direction, 60nm-width is replicated in the exposure area of 10 $\mathrm{mm} \times 10 \mathrm{~mm}$ size.

EB resist has high sensitivity and large edge roughness, and the resolution performance is bad. The amount of outgassing is low. KrF resist has small edge roughness and good resolution performance, but the amount of outgassing is a little high. From the result of evaluated CA positive-tone resist in EUV lithography, the resist that is optimized for $\mathrm{KrF}$ has better exposure characteristics than that of optimized for EB.

\section{References}

1. H. Kinoshita, K. Kurihara, Y. Ishii and Y. Torii:J.Vac. Sci. Technol. B7, 1648 (1989).

2. International Technology Roadmap for Semiconductors, International SEMATECH, 2000.

3. T. Watanabe, K. Mashima, M. Niibe and H. Kinoshita: Jpn. J. Appl. Phys. 36, 7579 (1997).

4. H. Kinoshita, T. Watanabe, D. Bajuk, J. Daniel, Y. Kimpara, M. Kriese and Y.
Platonov: Proc. SPIE 3767, 164 (1999).

5. T. Watanabe, H. Kinoshita, H. Nii, Y. Li, K. Hamamoto, T. Oshino, K. Sugisaki, K. Murakami, S. Irie, S. Shirayone, Y. Gomei and S. Okazaki: J. Vac. Sci. Technol. B18(6), 2905 (2000).

6. K. Hamamoto, T. Watanabe, H. Tsubakino, H. Kinoshita, T. Shoki and M. Hosoya: J Photopolym. Sci. Technol., 14(4), 567 (2001)

7. H. Kinoshita, T. Watanabe, M. Niibe, M. Ito,H. Oizumi, H. Yamanashi, K. Murakami, T. Oshino, Y. Platnov and N. Grupido: Proc. SPIE 3331, 20 (1998).

8. T. Watanabe, T. Haga, M. Niibe and $H$. Kinoshita: J. Synchrotron Rad. 5, 1149 (1998).

9. S. Hashimoto, A. Ando, S. Amano, Y. Haruyama, T. Hattori, K. Kanda, H. Kinoshita, S. Matsui, H. Mekaru, S. Miyamoto, T. Mochizuki, M. Niibe, Y. Shoji, Y. Utsumi, T. Watanabe, and H. Tsubakino: Trans. Materials Research Soc. Japan, 26[2] 783 (2001).

10. H. Ito and C. G. Wilson: Polym. Eng. Sci., 23, 1012 (1983).

11. T. Watanabe, H. Kinoshita, A. Miyafuji, S. Irie, S. Shirayone, S. Mori, E. Yano, H. Hada, K. Ohmori and H. Komono: Proc. SPIE 3997, 600 (2000).

12. T. Watanabe, K. Hamamoto, H. Kinoshita, H. Tsubakino, H. Hada, H. Komano, M. Endo and M.Sasago:J. Photoploym. Sci. Technol., 14(4) 555 (2001).

13. T. Watanabe, H. Kinoshita, H. Nii, K. Hamamoto, H. Tsubakino, H. Hada, H. Komano and S. Irie: J. Vac. Sci. Technol. B19(3), 736 (2001). 